\title{
Examination of levels pentraxin-3, interleukin-6, and C-reactive protein in rat model acute and chronic exercise
}

\author{
Melek Tunc-Ata*, Gunfer Turgut, Mukaddes Mergen-Dalyanoglu, Sebahat Turgut \\ Department of Physiology, Health Science, Pamukkale University, Denizli, Turkey
}

Different types of exercise occurs damage at the cellular level in the muscles. Muscle damage caused by exercise is determined creatine kinase, myoglobin, and increase in levels of acute phase protein and interleukin in blood. The purpose of this study was investigated the levels of pentraxin-3 (PTX-3), interleukin-6 (IL-6), and C-reactive protein (CRP) following acute and chronic exercising in rats. Twenty-six Wistar Albino male rats were divided in to three groups. A treadmill exercise was performed 3 days/week, $10 \mathrm{~min} /$ day for 1 week in acute groups. In chronic group, exercise performed 7 days/week, $60 \mathrm{~min} /$ day for 4 weeks. At the end of the experiment, plasma PTX-3, IL-6, and CRP levels were mea- sured. In current study, the PTX-3, IL-6, and CRP levels not observed statistically significant difference among control, acute, and chronic groups. The levels IL- 6 and CRP were not significantly different between acute and chronic exercise groups $(P>0.05)$. However, the level of PTX3 was found to be higher in the chronic group compared to the acute group $(P<0.05)$. The PTX-3 level increase on chronic exercise-induced muscle damage. Accorting to our results, we think that PTX-3 may have a protect role on muscle damage during chronic exercises.

Keywords: Acute exercise, Chronic exercise, Muscle damage, Training

\section{INTRODUCTION}

Routine exercise training of moderate intensity is known to enhance immune function (Walsh et al., 2011) and reduce risk of mortality (Liu et al., 2012; Sabia et al., 2012) cardiovascular diseases, obesity, and type 2 diabetes (Pedersen, 2006). However, an acute bout of prolonged ( $>1.5 \mathrm{hr}$ ) and/or strenuous exercise (55\%-75\% maximal $\mathrm{O}_{2}$ uptake) has also been shown to provoke muscle damage/soreness (Clarkson and Hubal, 2002), and elicit an acute inflammatory (Nieman et al., 2012), oxidative stress (Fisher et al., 2011) during the postexercise recovery period. Exhaustive and/or unaccustomed exercises (particularly those involving high intensity muscle contractions) are known to induce temporary muscle damage. This damage includes a series of events occurring. It causes damage to the sarcolemma and the muscle cell membrane. This damage results in the release of biochemical markers of muscle damage including (e.g., lactate dehydrogenase, creatine kinase, and myoglobin) (Torres et al., 2012). Exercise-induced muscle damage is classified into primary and the secondary damage (Howatson and van Someren, 2008). Primary muscle damage is related to morphological changes, including sarcomere (Z-disc, I, and A band), sarcolemma, sarcoplasmic reticulum, and cytoskeletal elements (Clarkson and Hubal, 2002). Secondary muscle damage occurs due to impaired calcium homeostasis and the inflammatory response (Tidball, 2005).

According to recent studies, contracting muscles release various cytokines called myokines. This finding has opened a new insight on the role of cytokines in modulating the muscle's metabolic and immunological responses to exercise. Different observations in cytokine responses to exercise are predominantly related to the intensity, mode and duration of exercise in addition to the participants' fitness levels, although differences in sensitivity and specificity of the assays should be considered. Acute bouts of intense or prolonged resistance exercise can induce an inflammatory response
${ }^{*}$ Corresponding author: Melek Tunc-Ata (iD http://orcid.org/0000-0002-0384-2356 Department of Physiology, Health Science, Pamukkale University, Denizli, Turkey Tel: +905444722023, Fax: +902582961729, E-mail: tuncmelekk@hotmail.com, Received: May 18, 2017 / Accepted: June 10, 2017
This is an Open Access article distributed under the terms of the Creative Commons Attribution Non-Commercial License (http://creativecommons.org/licenses/by-nc/4.0/) which permits unrestricted non-commercial use, distribution, and reproduction in any medium, provided the original work is properly cited. 
(Colbert et al., 2004). IL-6 could have a role during the inflammatory process in the enhancement of muscle damage or during the healing process. Today it is well established that IL- 6 is secreted by contracting skeletal muscle in the absence of muscle damage and that it plays important roles in the metabolic regulation (Steinbacher and Eckl, 2015).

CRP is an acute phase protein which increases remarkably during infection, inflammation and tissue damage (Borish and Steinke, 2003). It is mainly produced and secreted into circulation by liver in response to circulatory inflammatory mediators (Shoelson and Lee, 2006). CRP level is the best indicator to determine tissue damage because CRP increased immediately at early phase of tissue deterioration (Simopoulos, 2006). Recent studies reveal that CRP not only is an inflammatory mediator, but it plays very important role in inflammation (Peake et al., 2005).

Pentraxins are a group of multimeric proteins that are involved in acute immunologic responses. Short pentraxins (CRP and amyloid $\mathrm{P}$ protein) are synthesized by the liver in response to inflammatory signals. PTX-3 is the prototype of long pentraxins (molecular weight, $440 \mathrm{kDa}$ ) and is produced in response to inflammatory signals in various organs and tissues including vascular endothelial cells, smooth muscle cells, macrophages, adipose tissue, and liver (Deban et al., 2011). PTX-3, a marker of the acutephase inflammatory response, plays an important role in innate immunity and in modulation of the adaptive immune response (Yamasaki et al., 2009). Exercise-induced muscle damage is mainly diagnosed in two ways. The first way is the visualization methods, the other one is the observing the rates of enzyme activities exclusive to the muscle and levels of pro-inflammatory biomarkers in the plasma (Bazgir et al., 2015). In this study, we evaluated levels and the correlation of PTX-3, IL-6, and CRP following acute and chronic exercising in rats.

\section{MATERIALS AND METHODS}

\section{Animals and experimental conditions}

Twenty-six Wistar Albino 2-month-old male rats (200-250 g) were obtained from the Experimental Research Unit of the University of Pamukkale (Denizli, Turkey). They were reared under the supervision of a veterinarian, kept in well ventilated noises environment and allowed free axes to food and water. They were maintained on a 12/12 hr light-dark cycle under controlled temperature. All protocols used in this study were approved by the Pamukkale University Ethics Committee on animal research (PAUHDEK-2012/035).

\section{Experimental design}

The male animals were selected randomly and divided into three experimental groups: control $(n=10)$, acute $(n=7)$, and chronic $(n=9)$. The control group was not trained (sedentary). Acute exercise group; with $0.1 \%$ incline on the treadmill, 3 days/ week, $10 \mathrm{~min} /$ day, $20 \mathrm{~m} / \mathrm{min}$ was run. The rats in chronic exercise group; with $20 \%$ incline on the treadmill, for 4 weeks, 7 days/ week, $60 \mathrm{~min} /$ day, $0.1 \mathrm{~m} / \mathrm{min}$ was run. All of the animals were exercised at the same time of every day.

\section{Blood samples and measurements}

At the end of the experimental period, all the animals were anesthetized with ketamin/xylazine $\mathrm{HCl}(75 \mathrm{mg} / \mathrm{kg} / 10 \mathrm{mg} / \mathrm{kg}$ intraperitoneally). Blood samples were collected in heparinized tubes from the abdominal aorta of rats. Plasma samples were separated from cells by centrifugation at 3,000 rpm for $10 \mathrm{~min}$. and were stored at $-80^{\circ} \mathrm{C}$ until analysis. The plasma PTX-3, IL-6, and CRP concentrations were measured by an enzyme-linked immunosorbent assay (ELISA) method using an rat ELISA kit (SunRed Biotechnology Company, eBioscience An Affymetrix Company) in a multiplate ELISA reader (das, Digital and Analog Systems, Vimercate, MI, Italy).

\section{Statistical analysis}

Data was analyzed by IBM SPSS Statistics ver. 21.0 (IBM Co., Armonk, NY, USA). Continuous variables were expressed as mean \pm standard deviation and categorical variables as number and percent. Kruskal-Wallis variance analysis was used to compare more than two independent groups. Mann-Whitney $U$-test was used to compare two independent groups.

\section{RESULTS}

In current study, the PTX-3, IL-6, and CRP level was not observed statistically significant difference among control, acute, and chronic groups. There are not significantly different the concentration of IL- 6 and CRP between acute and chronic exercise group (Figs. 1, 2) $(P>0.05)$. The plasma levels of PTX-3 were found significantly increased in chronic exercise group compared to acute exercise group animals (Fig. 3) $(P<0.05)$.

\section{DISCUSSION}

According to our results, the IL-6 level was not changed in acute and chronic exercise groups compared to sedentary group. 


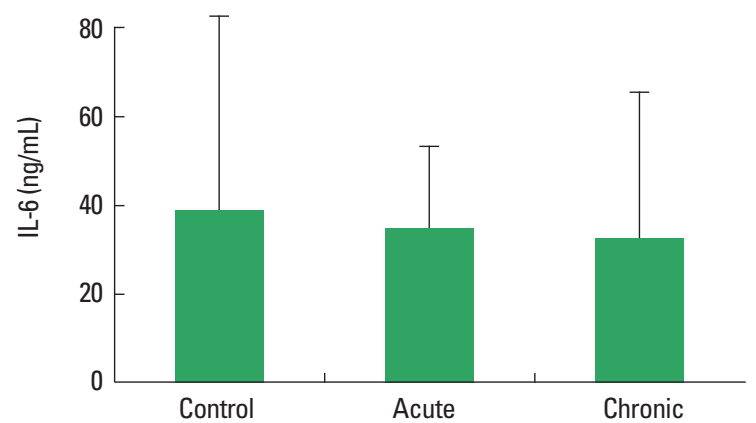

Fig. 1. Interleukin-6 (IL-6) plasma levels in groups.

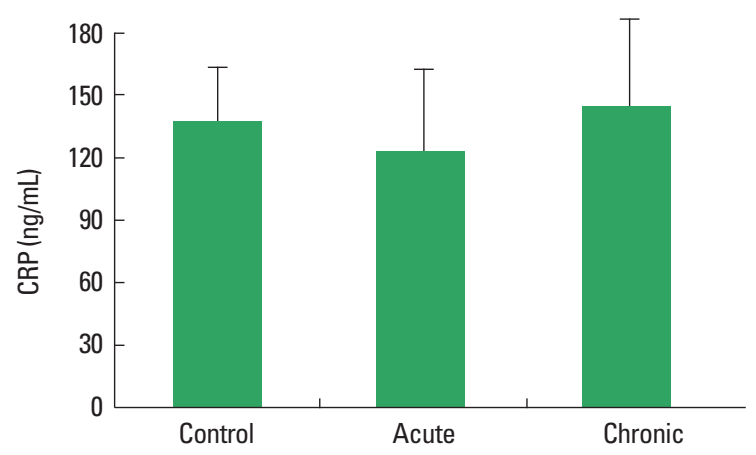

Fig. 2. C-reactive protein (CRP) plasma levels in groups.

An effective physical activity induces a series of changes in the immune system (Rosa Neto et al., 2009). It is known that the production of free oxygen radicals increased in the muscles and plasma during and following a highly severe contractile activity leads to muscle damage (Roebuck, 1999). The acute phase response activates the production of oxygen radicals together with various cytokines like interleukins and tumor necrosis factor- $\alpha$. The most prominent cytokine produced during the contractions is IL-6 which is expressed within the muscle cells and released into the blood (Nielsen and Pedersen, 2008). Fischer et al. (2004) reported that reduced IL- 6 mRNA response to exercise in trained human quadriceps muscle. Increased the IL-6 levels in both soleus and extensor digitorum longus muscles were reported in another study. Elevated IL-6 levels $48 \mathrm{hr}$ after the last exercise session of the 8 -week training period. The authors think that elevated muscular levels of IL-6 may be due to regeneration after injury (Isanejad et al., 2015). According to another study, plasma IL-6 concentration increases during different bouts of acute exercise (Pedersen and Febbraio, 2008). Kilıç et al. (2014) investigated that the possible role of moderate and strenuous swimming training on plasma and cerebrospinal fluid IL-6 levels during recovery from exhaustive exercise in rats. As a result of that study, plasma IL-6 lev-

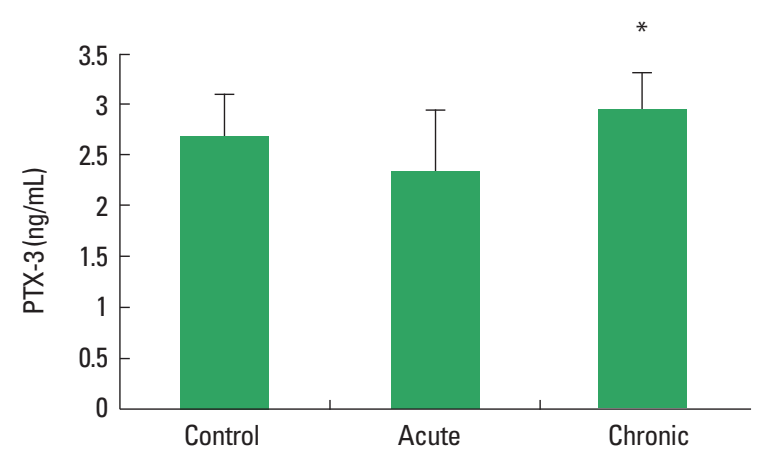

Fig. 3. Pentraxin-3 (PTX-3) plasma levels in groups. ${ }^{*} P<0.05$, significant between acute and chronic groups.

els were found unaltered among all groups. They conclude that exercise training intensity is an important factor determining IL-6 concentration after exhaustive exercise. In addition other researcher show that IL-6 expression was not affected by the training protocol (Lira et al., 2009). Mendham et al. (2011) demonstrated that the muscle damage response was notably augmented in the moderate-vigorous protocol compared to the low-intensity aerobic exercise, moderate-vigorous and low-intensity full-body resistance session protocols and this study evaluated the magnitude of the IL-6 response in light of the muscle damage response. The authors suggest that muscle damage may not be a major direct determinate of acute IL-6 release during exercise. Exercise training studies have reported equivocal results (decreases or no changes) in baseline levels of IL-6 (Nicklas et al., 2008). The results of previous studies investigating effects of muscle damage on IL-6 demonstrated conflicting results mainly depending on the type, duration, intensity of the exercise as well as the age at onset of exercise.

Plasma CRP concentrations in our study did not discriminate among all groups. Acute phase protein CRP have previously been reported to be associated with exercise-induced muscle damage, with evidence linking the stress and intensity of exercise to the subsequent magnitude of response of these markers within the circulation (Neubauer et al., 2008). Exercise training studies have uncertain results in levels of CRP (Donges et al., 2010). To date few studies report the acute exercise-induced CRP responses across different exercise modes and intensities within a sedentary, middle-aged cohort. Release of CRP is induced by IL-6 and responsible for recognition and clearance of damaged cells. (Neubauer et al., 2008) The present study indicates CRP to increase 24-hr postexercise within the higher-intensity protocols more so than the lower intensity protocols. Additionally, studies reporting the acute exercise-induced CRP response within a sedentary pop- 
ulation are minimal; with previous training studies reporting a lack of association between IL-6 and CRP (Donges et al., 2010; Nicklas et al., 2008).

A novel biomarker, PTX-3, primarily released by adipocytes, monocytes/macrophages (Savchenko et al., 2008) and neutrophils (Jaillon et al., 2007). PTX-3 is produced rapidly in damaged tissue and may reflect more of a tissue-specific inflammatory response that includes smooth and skeletal muscle and adipocytes (Introna et al., 1996). Nakajima et al., (2010) demonstrated that acute moderate and intense aerobic exercise elevates PTX-3 concentrations in untrained individuals. Decreased PTX-3 levels during 6 months of cardiac rehabilitation exercise was reported (Fukuda et al., 2012). On the contrary, another study show that increased PTX-3 levels after an acute bout of maximal aerobic and resistance exercise, which may have been the result of exercise induced muscle damage. Also plasma levels of PTX-3 are elevated in endurance trained individuals compared to controls. Miyaki et al. (2011, 2012) found that endurance trained males exhibit elevated baseline PTX-3 plasma levels compared to sedentary controls while 8 weeks of aerobic training increased both $\mathrm{VO}_{2}$ peak and resting plasma PTX-3 levels in elderly women. Therefore, increased PTX-3 release from the potentially damaged muscle due to acute maximal exercise would not be surprising. In our present study the levels of PTX-3 was found to be higher in the chronic group compared to the acute group. The differences in the results of the studies may be due to the type of exercise applied and the time of application.

We can say that accorting to our results, response to muscle damage of IL-6 and CRP not affected by acute and chronic exercise. Plasma PTX-3 was found significantly higher in the chronic group than acute group but not control animals. Because of this reason we think that PTX-3 may be an inflammatory marker of muscle damage in chronic exercise or it may be increased to protects against muscle damage in chronic exercise. Also there is need to further studies for clearing this subject.

\section{CONFLICT OF INTEREST}

No potential conflict of interest relevant to this article was reported.

\section{ACKNOWLEDGMENTS}

The authors thank the Pamukkale University Research Fund, which supported this research through project number $2015 \mathrm{HZ}$ L018.

\section{REFERENCES}

Bazgir B, Salesi M, Koushki M, Amirghofran Z. Effects of eccentric and concentric emphasized resistance exercise on IL-15 serum levels and its relation to inflammatory markers in athletes and non-athletes. Asian J Sports Med 2015;6:e27980.

Borish LC, Steinke JW. 2. Cytokines and chemokines. J Allergy Clin Immunol 2003;111(2 Suppl):S460-475.

Clarkson PM, Hubal MJ. Exercise-induced muscle damage in humans. Am J Phys Med Rehabil 2002;81(11 Suppl):S52-69.

Colbert LH, Visser M, Simonsick EM, Tracy RP, Newman AB, Kritchevsky SB, Pahor M, Taaffe DR, Brach J, Rubin S, Harris TB. Physical activity, exercise, and inflammatory markers in older adults: findings from the Health, Aging and Body Composition Study. J Am Geriatr Soc 2004;52:1098-1104.

Deban L, Jaillon S, Garlanda C, Bottazzi B, Mantovani A. Pentraxins in innate immunity: lessons from PTX3. Cell Tissue Res 2011;343:237-249.

Donges CE, Duffield R, Drinkwater EJ. Effects of resistance or aerobic exercise training on interleukin-6, C-reactive protein, and body composition. Med Sci Sports Exerc 2010;42:304-313.

Fischer CP, Hiscock NJ, Penkowa M, Basu S, Vessby B, Kallner A, Sjöberg LB, Pedersen BK. Supplementation with vitamins $C$ and $E$ inhibits the release of interleukin-6 from contracting human skeletal muscle. J Physiol 2004;558(Pt 2):633-645.

Fisher G, Schwartz DD, Quindry J, Barberio MD, Foster EB, Jones KW, Pascoe DD. Lymphocyte enzymatic antioxidant responses to oxidative stress following high-intensity interval exercise. J Appl Physiol (1985) 2011;110:730-737.

Fukuda T, Kurano M, Iida H, Takano H, Tanaka T, Yamamoto Y, Ikeda K, Nagasaki M, Monzen K, Uno K, Kato M, Shiga T, Maemura K, Masuda N, Yamashita H, Hirata Y, Nagai R, Nakajima T. Cardiac rehabilitation decreases plasma pentraxin 3 in patients with cardiovascular diseases. Eur J Prev Cardiol 2012;19:1393-1400

Howatson G, van Someren KA. The prevention and treatment of exercise-induced muscle damage. Sports Med 2008;38:483-503.

Introna M, Alles VV, Castellano M, Picardi G, De Gioia L, Bottazzai B, Peri G, Breviario F, Salmona M, De Gregorio L, Dragani TA, Srinivasan N, Blundell TL, Hamilton TA, Mantovani A. Cloning of mouse ptx3, a new member of the pentraxin gene family expressed at extrahepatic sites. Blood 1996;87:1862-1872.

Isanejad A, Saraf ZH, Mahdavi M, Gharakhanlou R, Shamsi MM, Paulsen $G$. The effect of endurance training and downhill running on the expression of IL-1 $\beta$, IL-6, and TNF- $\alpha$ and HSP72 in rat skeletal muscle. Cytokine 2015;73:302-308.

Jaillon S, Peri G, Delneste Y, Frémaux I, Doni A, Moalli F, Garlanda C, Ro- 
mani L, Gascan H, Bellocchio S, Bozza S, Cassatella MA, Jeannin P, Mantovani A. The humoral pattern recognition receptor PTX3 is stored in neutrophil granules and localizes in extracellular traps. J Exp Med 2007;204:793-804.

Kılıç M, Ulusoy Ö, Cırrık S, Hindistan IE, Ozkaya YG. Effect of exercise intensity on cerebrospinal fluid interleukin-6 concentration during recovery from exhaustive exercise in rats. Acta Physiol Hung 2014;101:21-31.

Kramer HF, Goodyear LJ. Exercise, MAPK, and NF-kappaB signaling in skeletal muscle. J Appl Physiol (1985) 2007;103:388-395.

Lira FS, Koyama CH, Yamashita AS, Rosa JC, Zanchi NE, Batista ML Jr, Seelaender MC. Chronic exercise decreases cytokine production in healthy rat skeletal muscle. Cell Biochem Funct 2009;27:458-461.

Liu R, Sui X, Laditka JN, Church TS, Colabianchi N, Hussey J, Blair SN. Cardiorespiratory fitness as a predictor of dementia mortality in men and women. Med Sci Sports Exerc 2012;44:253-259.

Mendham AE, Donges CE, Liberts EA, Duffield R. Effects of mode and intensity on the acute exercise-induced IL-6 and CRP responses in a sedentary, overweight population. Eur J Appl Physiol 2011;111:10351045.

Miyaki A, Maeda S, Choi Y, Akazawa N, Tanabe Y, Ajisaka R. Habitual aerobic exercise increases plasma pentraxin 3 levels in middle-aged and elderly women. Appl Physiol Nutr Metab 2012;37:907-911.

Miyaki A, Maeda S, Otsuki T, Ajisaka R. Plasma pentraxin 3 concentration increases in endurance-trained men. Med Sci Sports Exerc 2011;43:1217.

Nakajima T, Kurano M, Hasegawa T, Takano H, Iida H, Yasuda T, Fukuda T, Madarame H, Uno K, Meguro K, Shiga T, Sagara M, Nagata T, Maemura K, Hirata Y, Yamasoba T, Nagai R. Pentraxin3 and high-sensitive $\mathrm{C}$-reactive protein are independent inflammatory markers released during high-intensity exercise. Eur J Appl Physiol 2010;110:905-913.

Neubauer O, König D, Wagner KH. Recovery after an Ironman triathlon: sustained inflammatory responses and muscular stress. Eur J Appl Physiol 2008;104:417-426.

Nicklas BJ, Hsu FC, Brinkley TJ, Church T, Goodpaster BH, Kritchevsky $\mathrm{SB}$, Pahor M. Exercise training and plasma C-reactive protein and interleukin-6 in elderly people. J Am Geriatr Soc 2008;56:2045-2052.

Nielsen S, Pedersen BK. Skeletal muscle as an immunogenic organ. Curr Opin Pharmacol 2008;8:346-351.

Nieman DC, Konrad M, Henson DA, Kennerly K, Shanely RA, Wallner-Liebmann SJ. Variance in the acute inflammatory response to prolonged cycling is linked to exercise intensity. J Interferon Cytokine Res 2012;32:12-17.

Peake JM, Suzuki K, Wilson G, Hordern M, Nosaka K, Mackinnon L,
Coombes JS. Exercise-induced muscle damage, plasma cytokines, and markers of neutrophil activation. Med Sci Sports Exerc 2005;37:737745.

Pedersen BK. The anti-inflammatory effect of exercise: its role in diabetes and cardiovascular disease control. Essays Biochem 2006;42:105-117.

Pedersen BK, Febbraio MA. Muscle as an endocrine organ: focus on muscle-derived interleukin-6. Physiol Rev 2008;88:1379-1406.

Roebuck KA. Oxidant stress regulation of IL-8 and ICAM-1 gene expression: differential activation and binding of the transcription factors AP-1 and NF-kappaB (Review). Int J Mol Med 1999;4:223-230.

Rosa Neto JC, Lira FS, Oyama LM, Zanchi NE, Yamashita AS, Batista ML Jr, Oller do Nascimento CM, Seelaender M. Exhaustive exercise causes an anti-inflammatory effect in skeletal muscle and a pro-inflammatory effect in adipose tissue in rats. Eur J Appl Physiol 2009;106:697-704.

Sabia S, Dugravot A, Kivimaki M, Brunner E, Shipley MJ, Singh-Manoux A. Effect of intensity and type of physical activity on mortality: results from the Whitehall II cohort study. Am J Public Health 2012;102:698704.

Savchenko A, Imamura M, Ohashi R, Jiang S, Kawasaki T, Hasegawa G, Emura I, Iwanari H, Sagara M, Tanaka T, Hamakubo T, Kodama T, Naito M. Expression of pentraxin 3 (PTX3) in human atherosclerotic lesions. J Pathol 2008;215:48-55.

Shoelson SE, Lee J, Goldfine AB. Inflammation and insulin resistance. J Clin Invest 2006;116:1793-1801.

Simopoulos AP. Evolutionary aspects of diet, the omega-6/omega-3 ratio and genetic variation: nutritional implications for chronic diseases. Biomed Pharmacother 2006;60:502-507.

Steinbacher P, Eckl P. Impact of oxidative stress on exercising skeletal muscle. Biomolecules 2015;5:356-377.

Tidball JG. Inflammatory processes in muscle injury and repair. Am J Physiol Regul Integr Comp Physiol 2005;288:R345-353.

Torres R, Ribeiro F, Alberto Duarte J, Cabri JM. Evidence of the physiotherapeutic interventions used currently after exercise-induced muscle damage: systematic review and meta-analysis. Phys Ther Sport 2012;13:101-114.

Walsh NP, Gleeson M, Shephard RJ, Gleeson M, Woods JA, Bishop NC, Fleshner M, Green C, Pedersen BK, Hoffman-Goetz L, Rogers CJ, Northoff H, Abbasi A, Simon P. Position statement. Part one: Immune function and exercise. Exerc Immunol Rev 2011;17:6-63.

Yamasaki K, Kurimura M, Kasai T, Sagara M, Kodama T, Inoue K. Determination of physiological plasma pentraxin 3 (PTX3) levels in healthy populations. Clin Chem Lab Med 2009;47:471-477. 